\title{
Lipoprotein(a) and Its Potential Association with Thrombosis and Inflammation in COVID-19: a Testable Hypothesis
}

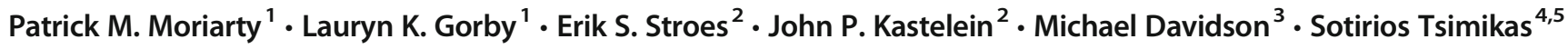 \\ Published online: 25 July 2020 \\ (C) Springer Science+Business Media, LLC, part of Springer Nature 2020
}

\begin{abstract}
Purpose of Review The COVID-19 pandemic has infected over $>11$ million as of today people worldwide and is associated with significant cardiovascular manifestations, particularly in subjects with preexisting comorbidities and cardiovascular risk factors. Recently, a predisposition for arterial and venous thromboses has been reported in COVID-19 infection. We hypothesize that besides conventional risk factors, subjects with elevated lipoprotein(a) ( $\operatorname{Lp}(a))$ may have a particularly high risk of developing cardiovascular complications.

Recent Findings The $\mathrm{Lp}(\mathrm{a})$ molecule has the propensity for inhibiting endogenous fibrinolysis through its apolipoprotein(a) component and for enhancing proinflammatory effects such as through its content of oxidized phospholipids. The LPA gene contains an interleukin-6 (IL-6) response element that may induce an acute phase-type increase in Lp(a) levels following a cytokine storm from COVID-19.

Summary Thus, subjects with either baseline elevated $\mathrm{Lp}$ (a) or those who have an increase following COVID-19 infection, or both, may be at very high risk of developing thromboses. Elevated Lp(a) may also lead to acute destabilization of preexisting but quiescent atherosclerotic plaques, which might induce acute myocardial infarction and stroke. Ongoing studies with IL-6 antagonists may be informative in understanding this relationship, and registries are being initiated to measure Lp(a) in subjects infected with COVID-19. If indeed an association is suggestive of being causal, consideration can be given to systematic testing of $\mathrm{Lp}(\mathrm{a})$ and prophylactic systemic anticoagulation in infected inpatients. Therapeutic lipid apheresis and pharmacotherapy for the reduction of $\mathrm{Lp}$ (a) levels may minimize thrombogenic potential and proinflammatory effects. We propose studies to test the hypothesis that Lp(a) may contribute to cardiovascular complications of COVID-19.
\end{abstract}

Keywords Lipoprotein(a) $\cdot$ COVID-19 $\cdot$ Fibrinolysis $\cdot$ Thrombosis $\cdot$ Inflammation

\section{Introduction}

The COVID-19 pandemic has infected millions of people around the world. Severity of respiratory distress and cardiovascular disease (CVD) in response to infection ranges from asymptomatic individuals to death. Respiratory failure is most often the cause of death in COVID-19 patients [1]. Patients

This article is part of the Topical Collection on Hot Topics in Atherosclerosis

Patrick M. Moriarty

pmoriart@kumc.edu

Sotirios Tsimikas

stsimikas@ucsd.edu

1 Division of Clinical Pharmacology, University of Kansas Medical Center, Kansas City, KS, USA

2 Department of Vascular Medicine, Academic Medical Center, Amsterdam, The Netherlands develop acute respiratory distress syndrome (ARDS) characterized by a rapid onset of bilateral inflammation in the lungs. The inflammation involves an acute increase in several proinflammatory cytokines, a process termed "cytokine storm." This severe inflammatory response causes increased leakiness of the blood vessels and an induction of a procoagulant state, eventually increasing the risk of multiorgan damage.

Lipid Clinic, The University of Chicago Pritzker School of Medicine, Chicago, IL, USA

4 Division of Cardiovascular Medicine, University of California San Diego, La Jolla, CA, USA

5 Vascular Medicine Program, Sulpizio Cardiovascular Center, University of California San Diego, 9500 Gilman Drive, BSB 1080, La Jolla, CA 92093-0682, USA 
Persistent elevation of cytokines, predominantly IL-1b and interleukin-6 (IL-6), predicts a higher likelihood of an unfavorable outcome, including death $[2,3]$. In addition to respiratory failure, data from China suggests that 20-30\% COVID-19 patients report cardiovascular injury, which contributes to $40 \%$ of deaths [4]. Most commonly, up to $30 \%$ of hospitalized subjects develop microangiopathy characterized by either microthrombi or clinically apparent deep venous thromboses and pulmonary emboli. In addition, myocardial injury, defined by elevated cardiac biomarkers such as high-sensitivity troponin I (hscTn1), was commonly found in non-survivors. The rise of hscTn1 follows the increase of inflammatory markers such as IL6 and may be a consequence of the cytokine storm $[5,6 \bullet]$. Finally, stroke in otherwise young individuals has been reported with no identified etiology to date. In view of the high rates of cardiovascular complications in patients infected with COVID-19, we propose that elevated Lp(a) levels should be studied as an etiological agent that links thrombosis and inflammation. We outline the rationale behind this hypothesis and propose avenues of research to address it [7•].

\section{COVID-19 and Risk of Thrombosis}

A predisposition for arterial and venous thromboembolic complications has been recently discovered as a result of COVID-19 infection. This might be due to the prolonged inflammatory response, decreased physical activity during infection, and reduced oxygen levels in the circulation. In a Dutch cohort study, $13 \%$ of hospitalized COVID-19 patients had symptomatic venous thromboembolism despite routine thrombosis prophylaxis, as compared with $0.85-2.89 \%$ in high-risk non-COVID-19 patients using thrombosis prophylaxis [8]. In COVID-19 patients admitted to the ICU, the rate of thrombotic complications increased to $31 \%$ [9]. Mechanistically, Harzallah et al. reported a positive lupus anticoagulant test in $45 \%$ of COVID-19 patients [10]. In addition, although antiphospholipid antibodies are directed to many antigens, a proportion have been shown to bind to oxidized phospholipids, which are also carried by $\operatorname{Lp}(\mathrm{a})[11$, 12]. Additionally, researchers at Mount Sinai Hospital have reported, over a 2-week period, a sevenfold increase in large vessel stroke for COVID-19 patients under 50 years old. Among these patients, all experienced either no or mild COVID-19 symptoms [7•]. Finally, Zhang and colleagues found that COVID-19infected patients presenting with thrombocytopenia, coagulopathy, and the presence of anticardiolipin antibodies had developed cerebral infarcts $[9,13 \bullet, 14-16]$.

\section{Lp(a) and Antifibrinolytic Effects}

$\mathrm{Lp}(\mathrm{a})$ is composed of an LDL particle bound to apolipoprotein(a) (apo(a)). Lp(a) is an independent risk factor for CVD, and levels are primarily genetically determined, with a small influence of environmental factors. Approximately, $20-30 \%$ of the world's population have an elevated Lp(a), defined as $>50 \mathrm{mg} / \mathrm{dL}$ or $>125 \mathrm{nmol} / \mathrm{L}$ [17]. There are exceptions to generally stable levels, including a stressful environment such as sepsis, in which Lp(a) levels are acutely elevated $[18,19]$. Normal lifestyle activities such as diet, exercise, and weight loss have limited effect on Lp(a), and lipid medications, such as statins, may modestly raise Lp(a) levels [20, 21]. Lp(a) may act as an acute phase reactant and has been noted to be increased in acute cardiovascular events [22-26]. There is currently no available pharmacotherapy approved by regulatory agencies which is targeted at the reduction of $\operatorname{Lp}(\mathrm{a})$, which limits therapeutic options solely to lipid apheresis.

Apo(a) is highly homologous to plasminogen but has no fibrinolytic activity. Data suggests that the apo(a) component of $\mathrm{Lp}(\mathrm{a})$ inhibits activation of plasminogen to plasmin by endogenous tissue plasminogen activators as well as competing for binding of plasminogen and plasmin to established fibrin clots, thus compromising clot lysis. Other potential prothrombotic actions by $\mathrm{Lp}$ (a) include an increase in the expression of PAI-1 to inhibit fibrinolysis and the inactivation of tissue factor pathway inhibitor (TFPI), which augments factor VII activation and promotes blood coagulation [27, 28].

In regard to venous thromboembolism (VTE), von Depka and colleagues analyzed the role of elevated Lp(a) levels $(>30 \mathrm{mg} / \mathrm{dL})$ in a population of 685 patients with at least one episode of VTE, compared with a control group, and discovered elevated $\mathrm{Lp}$ (a) levels were found in $20 \%$ of all patients, compared with $7 \%$ in the control group $(P<.001$, odds ratio [OR] 3.2, 95\% confidence interval [CI] 1.9-5.3) [29]. A recent meta-analysis of 90,904 individuals and 5029 stroke events found an association with Lp(a) when comparing high and low Lp(a) levels and revealed an estimated OR of 1.41 (95\% CI, 1.26-1.57) for case-control studies and an estimated RR of 1.29 (95\% CI, 1.06-1.58) for prospective trials [30]. However, other data and in particular genome-wide association studies have not supported a role of $\mathrm{Lp}(\mathrm{a})$ in VTE [31]. These data suggest that $\mathrm{Lp}(\mathrm{a})$ may be more relevant in clot propagation initiated by another primary etiologic agent, rather than clot initiation, and may tip the balance of endogenous coagulation and fibrinolysis to clot enlargement and clinical awareness. Interestingly, elevated Lp(a) levels have also been linked with childhood arterial ischemic strokes [32, 33].

\section{The Role of IL-6 in Plasma Lp(a) Levels}

Due to the strong association of inflammatory factors and poor clinical outcome, the FDA has provided emergency use 
authorizations and expedited initiation of clinical trials to evaluate various therapies targeted at cytokine reduction as treatment options for COVID-19 [34, 35•]. Anticytokine drugs which block IL-6 function using a monoclonal antibody against its receptor (e.g., tocilizumab) as well as apheresis therapy (Spectra Optia Apheresis System) for the removal of cytokines from blood have initiated clinical trials for COVID19, NCT04372186 and NCT04358003, respectively [36•, 37]. In conjunction with the ongoing clinical trial, the Spectra Optia Apheresis System with the Depuro D2000 Adsorption Cartridge received an emergency use authorization from the FDA to treat patients 18 years of age or older with confirmed COVID-19 admitted to the intensive care unit with confirmed or imminent respiratory failure. We hypothesize that in addition to the aforementioned risk factors, an elevated Lp(a) may indicate that an individual is at a higher risk of developing a severe reaction to COVID-19 infection, due to the extensive relationship between $\mathrm{Lp}(\mathrm{a})$ and multiple proinflammatory pathways, as well as proatherogenic and prothrombotic properties.

IL-6 is a $27 \mathrm{KD}$ cytokine involved in a variety of immune and inflammatory responses. Plasma levels are generally very low, but in the context of acute infection, plasma levels rise substantially due to increased production by a variety of cell types, including macrophages and T and B lymphocytes. IL-6 then participates in host defense functions, including potentiating the production of immunoglobulins and stimulating the production of acute phase proteins by the liver [38]. It has been shown that the genes of several such proteins contain an IL-6 response element (RE) CTGGGA, including the $L P A$ gene [39]. In fact, the promoter of the $L P A$ gene contains 5 IL-6 REs, but it appears that only IL-6 RE6 participates in upregulation of apo(a) production [40]. In view of these properties, one could postulate that during COVID-19 infection, the increases in plasma IL-6 levels, which can be more than 20-fold compared with baseline levels, could also upregulate hepatic apo(a) synthesis, leading to increased assembly and secretion into plasma of $\mathrm{Lp}$ (a) particles into the circulation (Fig. 1). In addition, although it has not been studied in COVID-19, it has been shown that OxPL are produced in the lungs of humans and animals infected with SARS, anthrax, or H5N1 [41]. Lp(a) is the preferential lipoprotein accumulator of OxPL [12] and has been shown to be responsible for many of its proinflammatory effects [42-44, 45•, 46••, 47].

$\mathrm{Lp}$ (a) has been documented to be an acute phase reactant in a variety of settings, including in myocardial infarction and acute coronary syndromes [22-24], post percutaneous coronary intervention $[25,26]$, major non-cardiac $[22,48]$ and cardiac surgery [22, 48, 49], Crohn's disease [50], and rheumatological disorders $[51,52]$, with an increase in Lp(a) levels more than $100 \%$ of baseline in some studies. In contrast, the effect of acute bacterial and viral infections on the plasma $\mathrm{Lp}$ (a) level has not been reported in the literature to the best of our knowledge, outside of one small study showing an approximate doubling of $\mathrm{Lp}$ (a) levels 4 months after infectious mononucleosis with Epstein-Barr virus [53].

In addition to preclinical studies in genetic, molecular biology and cell culture models, the relationship of IL-6 plasma levels to $\mathrm{Lp}(\mathrm{a})$ has been evaluated in several clinical studies. Horvath et al. [54] reported a strong relationship between Lp(a) and plasma IL-6, which seemed to be stronger in subjects with a higher number of KIV repeats on apo(a), which are also associated with lower Lp(a) levels. Additional clinical evidence has been provided with the approval of the IL-6 receptor (IL-6R) monoclonal antibody $(\mathrm{mAb})$ tocilizumab $[40,55,56]$. These studies have shown a $30-40 \%$ decrease in $\mathrm{Lp}$ (a) levels in response to tocilizumab that occurs within 1 month of therapy. In contrast, in an elegant study by Muller
Fig. 1 Relationship of IL-6 to LPA gene responses. In response to any proinflammatory stimulus, an increase in IL-6 may lead to IKL-6 binding to a response element in the LPA gene promoter, which then leads to higher production of apo(a) and $\mathrm{Lp}(\mathrm{a})$. The acute inflammatory state may also lead to generation of oxidized phospholipids that can bind to and be trafficked by $\mathrm{Lp}$ (a) particles. An acute increase in Lp(a)-OxPL may then predispose to acute thrombotic events by tilting the balance of coagulation to a prothrombotic state by inhibiting natural fibrinolysis

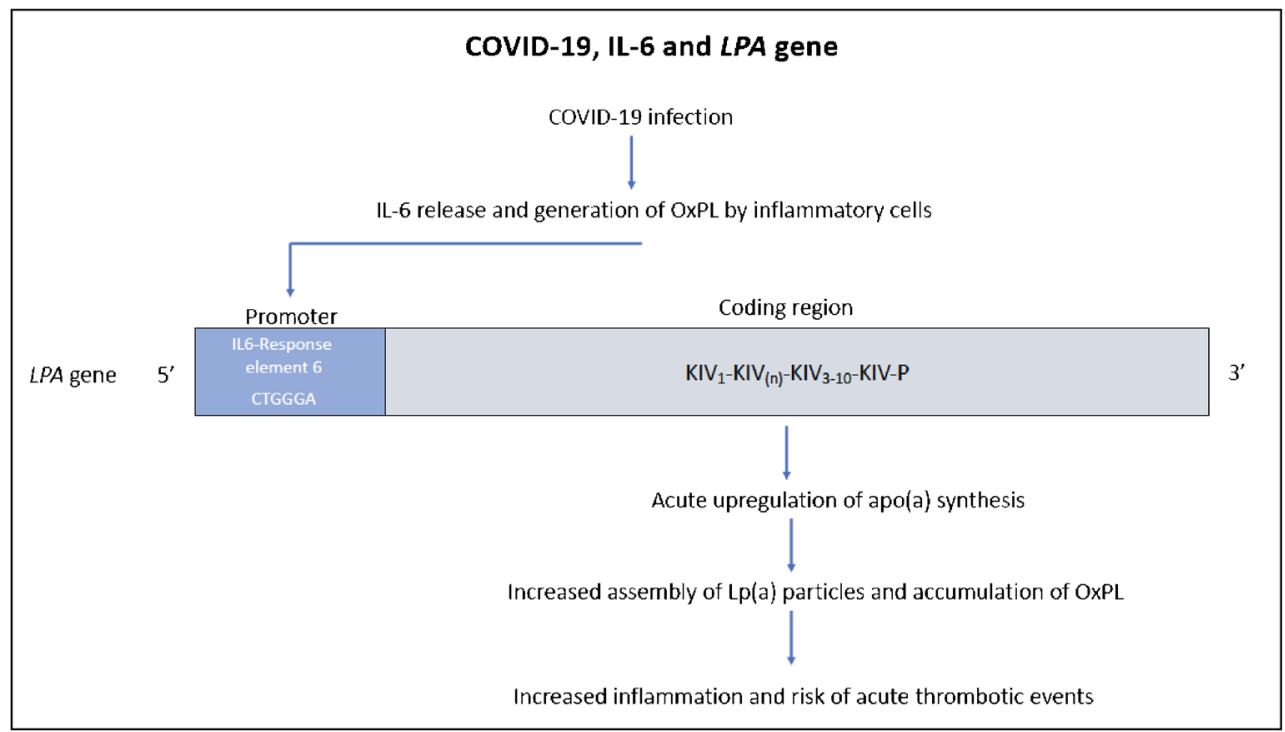


et al. [40], the anti-TNFalpha antibody (adalimumab) did not affect Lp(a) levels, showing a specific effect to IL-6 on Lp(a) biology as opposed to a generalized proinflammatory effect [40]. In addition, sarilumab another anti-IL-6R mAb has been shown to lower $\mathrm{Lp}$ (a) by $41 \%$ compared with $2.8 \%$ for adalimumab [57]. Both tocilizumab and sarilumab have completed phase 2 trials in severe COVID-19 patients, and phase 3 trials are currently underway.

The specificity of IL-6 in regulating Lp(a) was further demonstrated in 1153 subjects showing that subjects with elevated serum IL-6 also were more likely to have elevated Lp(a). In transcriptomic analysis of human liver biopsies, IL-6 response genes correlated with LPA gene expression in vivo. Furthermore, tocilizumab inhibited IL-6-induced $L P A$ mRNA and protein expression in human hepatocytes and the Lp(a)-lowering effect was mediated by the responsive element CTGGGA at promoter positions -46 to -40 [40].

\section{Prevalence of $L p(a)$ and Population Differences in Ethnic/Racial Groups}

While data is still being collected, the CDC has reported that racial and ethnic minority groups represent a greater proportion of COVID-19 patients relative to the percentage of the surrounding population. The preeminent driving force that determines disease severity in each individual is unclear, but a combination of socioeconomic status, age, and multiple comorbidities including weight, diabetes, hypertension, and CVD history likely plays a partial role [58]. Furthermore, living conditions including multigenerational households and densely populated neighborhoods are more common in minority groups. Working environment and types of employment can increase an individual's risk of exposure for those who have to continue working due to financial obligations. Hispanic workers are less likely to have access to paid sick leave compared with white non-Hispanic workers [59]. In the USA, African Americans appear to have an increased risk of morbidity and mortality in response to contracting COVID-19 infection and the disproportional response between races is currently not elucidated.

Estimates vary between individual states, but higher mortality has been documented in African Americans across the USA. For example, in Louisiana where African Americans make up $32 \%$ of the population, they account for $70 \%$ of the people who have died from COVID-19 and similar projections are being seen across the country [60•]. Compared with other races, individuals of African descent have a higher rate of elevated Lp(a), as well as larger sized lipoproteins, which is associated with an additional inflammatory risk, including IL6 elevations [54, 61]. Global estimates of Lp(a) levels are noted in Fig. 2.

Apolipoprotein E (APOE) may also be implicated in racial disparities in COVID-19. The APOE gene is composed of 3 alleles (E2, E3, and E4) with six genotypes (E2/ 2, E2/3, E2/4, E3/3, E3/4, and E4/4). The presence of APOE4 indicates a higher risk for developing CVD and dementia relative to the other isoforms [62, 63]. Subjects with African descent have a higher frequency of APOE4 genotypes, in addition to a higher mean Lp(a) level by 2-4fold compared with Caucasians [64]. Relative to those of European and Asian descent, individuals of African descent may have up to twice the frequency of the E4 allele $[65,66 \bullet \cdot$. APOE4 is also associated with a higher level of proinflammatory cytokines and promotes prothrombotic properties [67]. Furthermore, in an analysis of $>400,000$ individuals, apoE4 isoforms strongly influenced mass levels of $\mathrm{Lp}(\mathrm{a})$ with $65 \%$ higher $\mathrm{Lp}$ (a) levels in APOE4/4
Fig. 2 Global prevalence of elevated Lp(a) levels. Estimated prevalence of elevated $\mathrm{Lp}(\mathrm{a})(>$ $50 \mathrm{mg} / \mathrm{dL}$ or $>125 \mathrm{nmol} / \mathrm{L}$ ) is $>1$ billion people. Due to population differences in the presence of the number of $\mathrm{KIV}_{2}$ isoform repeats and other unknown factors, the population $\mathrm{Lp}(\mathrm{a})$ means are variable, with the highest mean levels present in subjects from Africa or with African descent. The lowest population $\mathrm{Lp}(\mathrm{a})$ means are present in subjects from South America and East Asia. Reprinted with permission from reference [61]

\section{Estimated World Population With Elevated $\mathrm{Lp}(\mathrm{a})>50 \mathrm{mg} / \mathrm{dL}=1.43$ Billion}

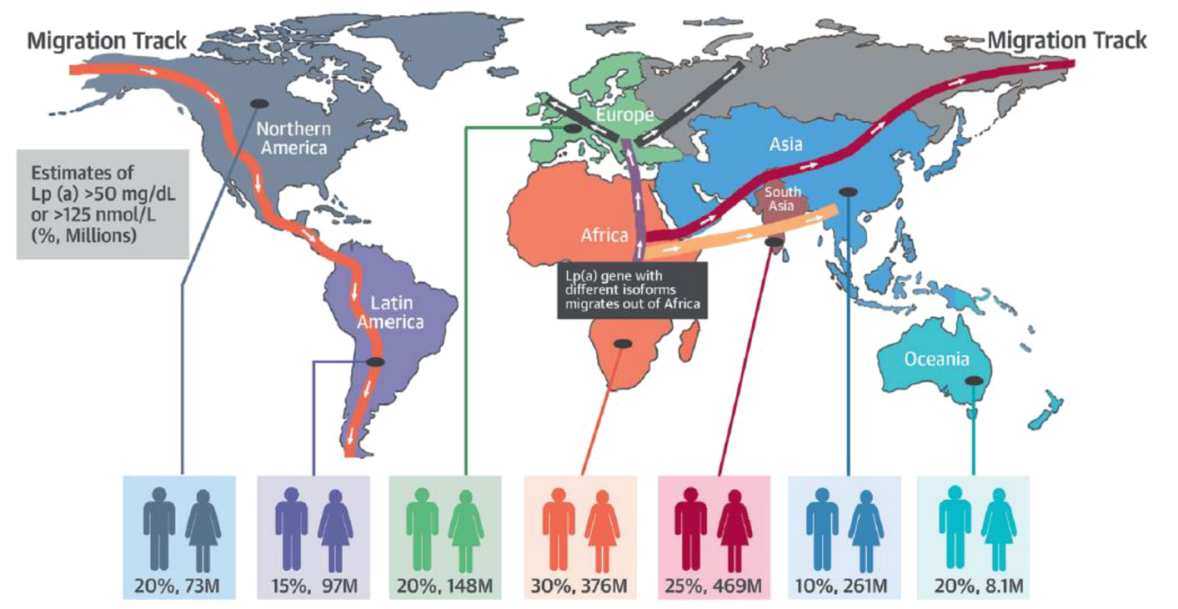


subjects (Fig. 3) [68••], linking the presence of apoE and Lp(a) in subjects with elevated levels of both. It has been suggested that, possibly due to an increase innate immune response, individuals with an $A P O E 4$ polymorphism may be at a higher risk for a severe response to COVID-19 [66••]. Whether APOE genotypes influence the prognosis of COVID-19 has not been explored to date.

\section{Proposals for Research in COVID-19 to Define a Potential Role in Lp(a) in COVID-19 Infection}

The observation that COVID-19 is associated with a very high rate of thromboses, its relationship to the cytokine storm and specifically with high levels of IL-6, coupled with IL-6's ability to strongly upregulate Lp(a) levels, and the high homology of $\mathrm{Lp}$ (a) to plasminogen, suggests the hypothesis that some of the prothrombotic and inflammatory effects of COVID-19 may be emanating from either baseline elevated Lp(a) or acute increases in $\mathrm{Lp}(\mathrm{a})$. We propose the following studies to evaluate this hypothesis:

1. Measure Lp(a) serially in hospitalized subjects and analyze according to the incidence of thrombotic phenotypes. Consider measurement of OxPL-apoB levels to identify $\mathrm{Lp}$ (a) particles with particularly high OxPL content that may reflect high oxidative stress and potential for inflammation and procoagulant effects. This could be enhanced

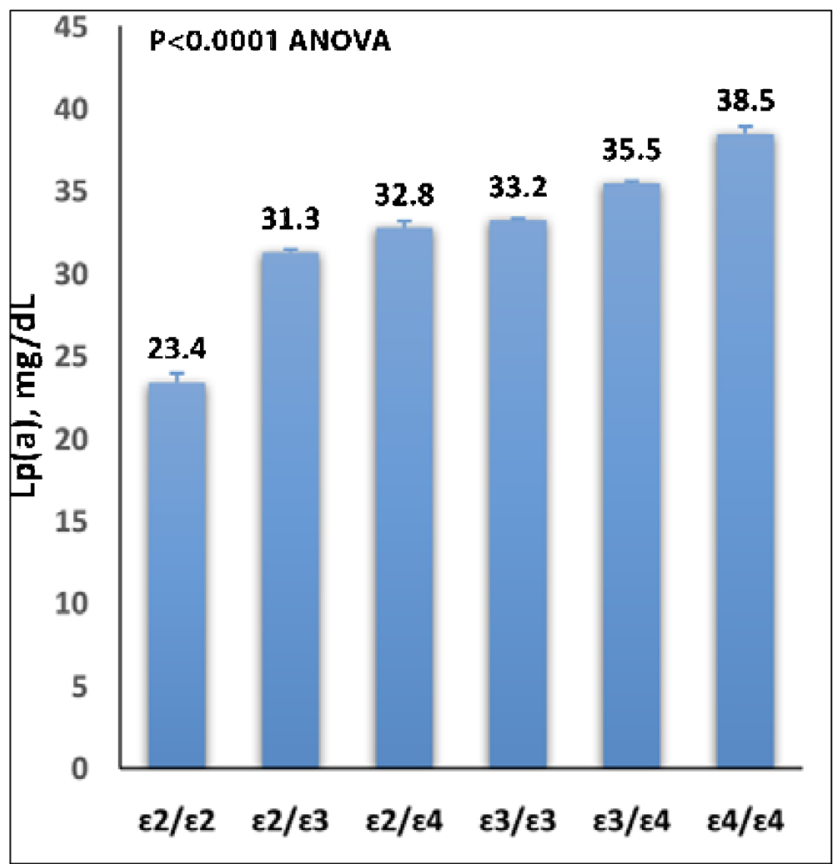

Fig. 3 Relationship of $A P O E$ genotypes to $\mathrm{Lp}$ (a) mass. Corresponding mean (SD) $\mathrm{Lp}$ (a) levels increased significantly according to $A P O E$ genotype ranging from 23.4 for $\varepsilon 2 / \varepsilon 2$ to 38.5 (44.1) $\mathrm{mg} / \mathrm{dL}$ for $\varepsilon 4 / \varepsilon 4$ $(P<0.0001$; ANOVA). Median Lp(a) levels also increased by genotype, from 11 for $\varepsilon 2 / \varepsilon 2$ to $20 \mathrm{mg} / \mathrm{dL}$ for $\varepsilon 4 / \varepsilon 4$ by organizing consortia and pooling data for additional power (Dutch COVID-19 biobank, Columbia University COVID-19 biobank, UK biobank coronavirus research, etc.). This will define the prevalence of baseline elevated Lp(a) in subjects hospitalized with COVID-19 and also assess temporal changes in levels. The population prevalence of $\mathrm{Lp}(\mathrm{a})$ is well known, and any deviation for this would suggest a potential link [69].

2. Measure Lp(a) in subjects presenting with COVID-19 and VTE, pulmonary emboli, acute ST-elevation MI, and acute stroke; those who are troponin positive; and those presenting with other manifestations of CVD, such as heart failure and myocarditis. In particular, the transition of a stable plaque to an inflamed, prothrombotic one may be highly relevant to $\mathrm{Lp}(\mathrm{a})-\mathrm{OxPL}$ as an etiologic entity [70].

3. Measure $\mathrm{Lp}(\mathrm{a})$ at serial time points in ongoing clinical trials of IL-6 inhibitors and other cytokine-directed therapies and assess whether levels change in response to IL-6 inhibition. We hypothesize that Lp(a) levels would increase significantly in subjects treated with the control and this rise would be blunted in subjects treated with IL-6-directed therapy. In prior studies with IL-6 antagonists in patients with rheumatoid arthritis, this effect entailed a $30 \%$ reduction $[51,52]$.

4. Correlate baseline levels and the change in $\mathrm{Lp}(\mathrm{a})$ levels with prothrombotic and inflammatory biomarkers measured.

5. Assess if an association is present with $\mathrm{Lp}$ (a) levels and ICU/ventilation parameters and in-hospital and long-term outcomes.

With the association of high rates of thrombotic complications in COVID-19 patients, efforts are already underway to assess for clinically silent DVT/PE and to treat with systemic anticoagulation. Such a process can be considered for study as a prophylactic measure in subjects with elevated Lp(a).

If indeed an association is shown and is suggestive of being causal, consideration can also be given to lipid apheresis which was recently approved by the FDA as a therapeutic option for elevated $\mathrm{Lp}$ (a) (>60 mg/dL) in conjunction with CVD and persistently elevated LDL-C $>100 \mathrm{mg} / \mathrm{dL}$. Lipid apheresis has been shown to rapidly reduce $\mathrm{Lp}$ (a) levels substantially and also to improve blood rheology as well as reduce apoE4 isoforms and inflammatory markers, including IL-6 and oxidized phospholipids [71, 72]. In fact, lipid apheresis has been shown to reduce the frequency of refractory angina and improved magnetic resonance imaging measured coronary blood flow in subjects with elevated Lp(a) [73]. Consideration should be given to initiating pharmacotherapy trials using RNA therapeutics [74•, 75] which can lower $\operatorname{Lp}(\mathrm{a})>80 \%$ and which are currently in phase 2 and 3 outcome studies, respectively, to assess whether this may improve prognosis. 
In conclusion, the confluence of a large variety of cardiovascular complications in COVID-19 patients, which have the commonality of both thromboses and inflammation, may support the hypothesis that one potential etiological agent in the clinical course is elevated $\mathrm{Lp}(\mathrm{a})$. Testing this hypothesis is straightforward and would simply require the measurement of Lp(a) levels in several clinical scenarios of the COVID-19 presentation and assessing relationships to clinical phenotypes that may be linked pathophysiologically. We urge interested parties to participate in such clinical research to further understand if a potential role exists and if so to consider $\mathrm{Lp}$ (a)-lowering approaches to minimize cardiovascular complications.

\section{Compliance with Ethical Standards}

Conflict of Interest Erik Stroes reports personal fees from Amgen, Akcea, Sanofi-Regeneron, Esperion, and Novartis outside the submitted work. John Kastelein reports personal fees from AstraZeneca, CIVI Biotechnology, CSL Behring, Draupnir, Esperion, Gemphire, Madrigal Pharmaceuticals, Matinas BioPharma, NorthSea Therapeutics, Novo Nordisk, Novartis, Regeneron, RegenXBio, Staten Biotech, 89Bio, Omeicos, and Serometrix outside the submitted work. Michael Davidson reports he is the Chief Medical Officer of Corvidia Therapeutics. Sotirios Tsimikas reports personal fees from Ionis Pharmaceuticals, being cofounder of Oxitope, Inc., and Kleanthi Diagnostics, LLC, outside the submitted work. In addition, Dr. Tsimikas has a patent for methods of identifying a subject having or at risk of having or developing coronary artery disease with royalties paid to Kleanthi Diagnostics; two patents for methods for assessing atherogenesis by determining oxidized phospholipid to apolipoprotein B ratios with royalties paid to Kleanthi Diagnostics; and a patent for oxidative biomarkers in predicting risk of stroke, transient ischemic attack (TIA), and peripheral arterial disease (PAD) with royalties paid to Kleanthi Diagnostics. Patrick M. Moriarty and Lauryn K. Gorby declare no conflicts of interest relevant to this manuscript.

Human and Animal Rights and Informed Consent This article does not contain any studies with human or animal subjects performed by any of the authors.

\section{References}

Papers of particular interest, published recently, have been highlighted as:

- Of importance

.• Of major importance

1. Chen T, Wu D, Chen H, Yan W, Yang D, Chen G, et al. Clinical characteristics of 113 deceased patients with coronavirus disease 2019: retrospective study. BMJ. 2020;368:m1091. https://doi.org/ 10.1136/bmj.m1091.

2. Voiriot G, Razazi K, Amsellem V, Tran Van Nhieu J, Abid S, Adnot $\mathrm{S}$, et al. Interleukin-6 displays lung anti-inflammatory properties and exerts protective hemodynamic effects in a double-hit murine acute lung injury. Respir Res. 2017;18(1):64. https://doi. org/10.1186/s12931-017-0553-6.

3. Gong J, Dong H, Xia SQ, Huang YZ, Wang D, Zhao Y et al. Correlation analysis between disease severity and inflammationrelated parameters in patients with COVID-19 pneumonia.
medRxiv. 2020:2020.02.25.20025643. https://doi.org/10.1101/ 2020.02.25.20025643.

4. Akhmerov A, Marbán E. COVID-19 and the heart. Circ Res. 2020;126(10):1443-55.

5. Clerkin KJ, Fried JA, Raikhelkar J, Sayer G, Griffin JM, Masoumi A, et al. Coronavirus disease 2019 (COVID-19) and cardiovascular disease. Circulation. 2020;141:1648-55. https://doi.org/10.1161/ circulationaha.120.046941.

6. Klok FA, Kruip M, Van der Meer N, Arbous M, Gommers D, Kant $\mathrm{K}$, et al. Incidence of thrombotic complications in critically ill ICU patients with COVID-19. Thromb Res. 2020:191;145-147. https://doi.org/10.1016/j.thromres.2020.04.013. Demonstrates inflammatory markers such as IL-6 trend with troponin levels as a consequence of cytokine storm and myocardial injury association with COVID-19.

7. Oxley TJ, Mocco J, Majidi S, Kellner CP, Shoirah H, Singh IP, et al. Large-vessel stroke as a presenting feature of Covid-19 in the young. N Engl J Med. 2020:e60. https://doi.org/10.1056/ NEJMc2009787 Single-site analysis showing evidence for higher risk for large vessel stroke in young individuals with mild COVID-19 symptoms.

8. Middeldorp S, Coppens M, van Haaps TF, Foppen M, Vlaar AP, Müller MCA, et al. Incidence of venous thromboembolism in hospitalized patients with COVID-19. J Thromb Haemost. n/a(n/a). https://doi.org/10.1111/jth.14888.

9. Klok FA, Kruip M, van der Meer NJM, Arbous MS, Gommers D, Kant KM, et al. Incidence of thrombotic complications in critically ill ICU patients with COVID-19. Thromb Res. 2020;191:145-7. https://doi.org/10.1016/j.thromres.2020.04.013.

10. Harzallah I, Debliquis A, Drénou B. Lupus anticoagulant is frequent in patients with Covid-19. J Thromb Haemost. n/a(n/a), https://doi.org/10.1111/jth.14867.

11. Hörkkö S, Miller E, Dudl E, Reaven P, Curtiss LK, Zvaifler NJ, et al. Antiphospholipid antibodies are directed against epitopes of oxidized phospholipids. Recognition of cardiolipin by monoclonal antibodies to epitopes of oxidized low density lipoprotein. J Clin Invest. 1996;98(3):815-25.

12. Leibundgut G, Scipione C, Yin H, Schneider M, Boffa MB, Green $\mathrm{S}$, et al. Determinants of binding of oxidized phospholipids on apolipoprotein (a) and lipoprotein (a). J Lipid Res. 2013;54(10): 2815-30. https://doi.org/10.1194/jlr.M040733.

13. Zhang Y, Xiao M, Zhang S, Xia P, Cao W, Jiang W, et al. Coagulopathy and antiphospholipid antibodies in patients with Covid-19. N Engl J Med. 2020;382(17):e38. https://doi.org/10. 1056/NEJMc2007575 COVID-19-infected patients presenting with thrombocytopenia, coagulopathy, and the presence of anticardiolipin antibodies had developed cerebral infarcts.

14. Tam C-CF, Cheung K-S, Lam S, Wong A, Yung A, Sze M, et al. Impact of coronavirus disease 2019 (COVID-19) outbreak on STsegment-elevation myocardial infarction care in Hong Kong, China. Circ Cardiovasc Qual Outcomes. 2020;13(4):e006631.

15. Xie Y, Wang X, Yang P, Zhang S. COVID-19 complicated by acute pulmonary embolism. Radiol Cardiothorac Imaging. 2020;2(2):e200067.

16. Marone EM, Rinaldi LF. Upsurge of deep venous thrombosis in patients affected by COVID-19: Preliminary data and possible explanations. J Vasc Surg Venous Lymphat Disord. (2020);8(4):694 695. https://doi.org/10.1016/j.jvsv.2020.04.004.

17. Enas EA, Varkey B, Dharmarajan TS, Pare G, Bahl VK. Lipoprotein(a): an independent, genetic, and causal factor for cardiovascular disease and acute myocardial infarction. Indian Heart J. 2019;71(2):99-112. https://doi.org/10.1016/j.ihj.2019.03.004.

18. Topciu Shufta V, Begolli L, Kryeziu E. Lipoprotein (a) as an acute phase reactant in patients on chronic hemodialysis. Bosn J Basic Med Sci. 2010;10(1):19-25. https://doi.org/10.17305/bjbms.2010. 2728. 
19. Tsimikas S. A test in context: lipoprotein(a): diagnosis, prognosis, controversies, and emerging therapies. J Am Coll Cardiol. 2017;69(6):692-711. https://doi.org/10.1016/j.jacc.2016.11.042.

20. Tsimikas S, Gordts PL, Nora C, Yeang C, Witztum JL. Statins and increases in Lp (a): an inconvenient truth that needs attention. Eur Heart J. 2020;41(1):192-3.

21. Tsimikas S, Gordts PL, Nora C, Yeang C, Witztum JL. Statin therapy increases lipoprotein (a) levels. Eur Heart J. 2019:41(24);22752284. https://doi.org/10.1093/eurheartj/ehz310.

22. Maeda S, Abe A, Seishima M, Makino K, Noma A, Kawade M. Transient changes of serum lipoprotein(a) as an acute phase protein. Atherosclerosis. 1989;78(2-3):145-50. https://doi.org/10.1016/ 0021-9150(89)90218-9.

23. Tsimikas S, Bergmark C, Beyer RW, Patel R, Pattison J, Miller E, et al. Temporal increases in plasma markers of oxidized low-density lipoprotein strongly reflect the presence of acute coronary syndromes. J Am Coll Cardiol. 2003;41(3):360-70. https://doi.org/ 10.1016/s0735-1097(02)02769-9.

24. Tsimikas S, Witztum JL, Miller ER, Sasiela WJ, Szarek M, Olsson AG, et al. High-dose atorvastatin reduces total plasma levels of oxidized phospholipids and immune complexes present on apolipoprotein B-100 in patients with acute coronary syndromes in the MIRACL trial. Circulation. 2004;110(11):1406-12. https://doi.org/ 10.1161/01.CIR.0000141728.23033.B5.

25. Tsimikas S, Lau HK, Han KR, Shortal B, Miller ER, Segev A, et al. Percutaneous coronary intervention results in acute increases in oxidized phospholipids and lipoprotein(a): short-term and longterm immunologic responses to oxidized low-density lipoprotein. Circulation. 2004;109(25):3164-70. https://doi.org/10.1161/01. CIR.0000130844.01174.55.

26. Nakamura A, Kanazawa M, Kagaya Y, Kondo M, Sato K, Endo H, et al. Plasma kinetics of mature PCSK9, furin-cleaved PCSK9, and Lp (a) with or without administration of PCSK9 inhibitors in acute myocardial infarction. J Cardiol. 2020. https://doi.org/10.1016/j. jjcc.2020.04.006.

27. Buechler C, Ullrich H, Ritter M, Porsch-Oezcueruemez M, Lackner $\mathrm{KJ}$, Barlage S, et al. Lipoprotein (a) up-regulates the expression of the plasminogen activator inhibitor 2 in human blood monocytes. Blood. 2001;97(4):981-6.

28. Caplice NM, Panetta C, Peterson TE, Kleppe LS, Mueske CS, Kostner GM, et al. Lipoprotein (a) binds and inactivates tissue factor pathway inhibitor: a novel link between lipoproteins and thrombosis. Blood. 2001;98(10):2980-7.

29. von Depka M, Nowak-Göttl U, Eisert R, Dieterich C, Barthels M, Scharrer I, et al. Increased lipoprotein (a) levels as an independent risk factor for venous thromboembolism. Blood. 2000;96(10): 3364-8.

30. Nave AH, Lange KS, Leonards CO, Siegerink B, Doehner W, Landmesser U, et al. Lipoprotein (a) as a risk factor for ischemic stroke: a meta-analysis. Atherosclerosis. 2015;242(2):496-503.

31. Larsson SC, Gill D, Mason AM, Jiang T, Bäck M, Butterworth AS, et al. Lipoprotein (a) in Alzheimer, atherosclerotic, cerebrovascular, thrombotic, and valvular disease: Mendelian randomization investigation. Circulation. 2020;141(22):1826-8.

32. McNeal CJ. Lipoprotein(a): its relevance to the pediatric population. J Clin Lipidol. 2015;9(5 Suppl):S57-66. https://doi.org/10. 1016/j.jacl.2015.07.006

33. Helgadottir A, Gretarsdottir S, Thorleifsson G, Holm H, Patel RS, Gudnason T, et al. Apolipoprotein (a) genetic sequence variants associated with systemic atherosclerosis and coronary atherosclerotic burden but not with venous thromboembolism. J Am Coll Cardiol. 2012;60(8):722-9.

34. Eastman RT, Roth JS, Brimacombe KR, Simeonov A, Shen M, Patnaik S, Hall MD. Remdesivir: A Review of Its Discovery and Development Leading to Emergency Use Authorization for
Treatment of COVID-19. ACS Cent Sci. (2020);6(5):672-683. https://doi.org/10.1021/acscentsci.0c00489.

35. Ma J, Xia P, Zhou Y, Liu Z, Zhou X, Wang J, et al. Potential effect of blood purification therapy in reducing cytokine storm as a late complication of critically ill COVID-19. Clin Immunol. 2020;214: 108408. https://doi.org/10.1016/j.clim.2020.108408 A study demonstrating that the apheresis reduction of plasma cytokines may potentially improve late complications of critically ill COVID-19 patients.

36. $\mathrm{Fu} \mathrm{B}, \mathrm{Xu} \mathrm{X}$, Wei $\mathrm{H}$. Why tocilizumab could be an effective treatment for severe COVID-19? J Transl Med. 2020;18(1):164. https:// doi.org/10.1186/s12967-020-02339-3 An interesting review outlining that the mechanism and function of a monoclonal antibody antagonist to $\mathrm{IL}-6$ receptor may be effective in the treatment of COVID-19.

37. Administration USFaD. Coronavirus (COVID-19) update: FDA authorizes blood purification device to treat COVID-19. https:// www.fda.gov/news-events/press-announcements/coronaviruscovid-19-update-fda-authorizes-blood-purification-device-treatcovid-192020. Accessed 10 Apr 2020.

38. Akira S, Isshiki H, Sugita T, Tanabe O, Kinoshita S, Nishio Y, et al. A nuclear factor for IL-6 expression (NF-IL6) is a member of a C/EBP family. EMBO J. 1990;9(6):1897-906.

39. Wade DP, Clarke JG, Lindahl GE, Liu AC, Zysow BR, Meer K, et al. $5^{\prime}$ control regions of the apolipoprotein(a) gene and members of the related plasminogen gene family. PNAS. 1993;90(4):136973.

40. Muller N, Schulte DM, Turk K, Freitag-Wolf S, Hampe J, Zeuner R, et al. IL-6 blockade by monoclonal antibodies inhibits apolipoprotein (a) expression and lipoprotein (a) synthesis in humans. J Lipid Res. 2015;56(5):1034-42. https://doi.org/10.1194/jlr. P052209.

41. Imai Y, Kuba K, Neely GG, Yaghubian-Malhami R, Perkmann T, van Loo G, et al. Identification of oxidative stress and toll-like receptor 4 signaling as a key pathway of acute lung injury. Cell. 2008;133(2):235-49.

42. Tsimikas S, Willeit $\mathrm{P}$, Willeit J, Santer $\mathrm{P}$, Mayr M, Xu Q, et al. Oxidation-specific biomarkers, prospective 15-year cardiovascular and stroke outcomes, and net reclassification of cardiovascular events. J Am Coll Cardiol. 2012;60(21):2218-29. https://doi.org/ 10.1016/j.jacc.2012.08.979.

43. van der Valk FM, Bekkering S, Kroon J, Yeang C, Van den Bossche J, van Buul JD, et al. Oxidized phospholipids on lipoprotein(a) elicit arterial wall inflammation and an inflammatory monocyte response in humans. Circulation. 2016;134(8):611-24. https://doi.org/10.1161/CIRCULATIONAHA.116.020838.

44. Sun X, Seidman JS, Zhao P, Troutman TD, Spann NJ, Que X, et al. Neutralization of oxidized phospholipids ameliorates non-alcoholic steatohepatitis. Cell Metab. 2020;31(1):189-206 e8. https://doi.org/ 10.1016/j.cmet.2019.10.014.

45. Stiekema LCA, Prange KHM, Hoogeveen RM, Verweij SL, Kroon J, Schnitzler JG, et al. Potent lipoprotein(a) lowering following apolipoprotein(a) antisense treatment reduces the pro-inflammatory activation of circulating monocytes in patients with elevated lipoprotein(a). Eur Heart J. 2020;41(24):2262-2271. https://doi. org/10.1093/eurheartj/ehaa171. The antisense apolipoprotein(a) therapy reduces proinflammatory activation of circulating monocytes in addition to lipoprotein(a).

46.• Schnitzler JG, Hoogeveen RM, Ali L, KHM P, Waissi F, van Weeghel M, et al. Atherogenic lipoprotein(a) increases vascular glycolysis, thereby facilitating inflammation and leukocyte extravasation. Circ Res. 2020;126(10):1346-59. https://doi.org/10.1161/ CIRCRESAHA.119.316206 Lipoprotein(a) appears to activate inflammation and extravasation through a process of vascular glycolysis. 
47. Que X, Hung MY, Yeang C, Gonen A, Prohaska TA, Sun X, et al. Oxidized phospholipids are proinflammatory and proatherogenic in hypercholesterolaemic mice. Nature. 2018;558(7709):301-6. https://doi.org/10.1038/s41586-018-0198-8.

48. Noma A, Abe A, Maeda S, Seishima M, Makino K, Yano Y, et al. Lp(a): an acute-phase reactant? Chem Phys Lipids. 1994;67-68: 411-7.

49. Kaklikkaya I, Ozdemir R, Orem A, Unal M, Sonmez B, Ozcan F. Course of serum lipoprotein(a) and acute phase protein levels in patients undergoing open heart surgery. J Cardiovasc Surg (Torino). 2002;43(6):811-5

50. Koutroubakis IE, Malliaraki N, Vardas E, Ganotakis E, Margioris $\mathrm{AN}$, Manousos ON, et al. Increased levels of lipoprotein (a) in Crohn's disease: a relation to thrombosis? Eur J Gastroenterol Hepatol. 2001;13(12):1415-9. https://doi.org/10.1097/00042737200112000-00004.

51. Ledue TB, Neveux LM, Palomaki GE, Ritchie RF, Craig WY. The relationship between serum levels of lipoprotein(a) and proteins associated with the acute phase response. Clin Chim Acta. 1993;223(1-2):73-82.

52. Asanuma Y, Kawai S, Aoshima H, Kaburaki J, Mizushima Y. Serum lipoprotein(a) and apolipoprotein(a) phenotypes in patients with rheumatoid arthritis. Arthritis Rheum. 1999;42(3):443-7. https://doi.org/10.1002/1529-0131(199904)42:3<443::AIDANR8 $>3$.0.CO;2-Q

53. Apostolou F, Gazi IF, Lagos K, Tellis CC, Tselepis AD, Liberopoulos $\mathrm{EN}$, et al. Acute infection with Epstein-Barr virus is associated with atherogenic lipid changes. Atherosclerosis. 2010;212(2):607-13. https://doi.org/10.1016/j.atherosclerosis.2010.06.006.

54. Horvath L, Csaszar A, Falus A, Dieplinger H, Horvath A, Puskas E, et al. IL-6 and lipoprotein(a) [LP(a)] concentrations are related only in patients with high $\mathrm{APO}(\mathrm{a})$ isoforms in monoclonal gammopathy. Cytokine. 2002;18(6):340-3. https://doi.org/10.1006/cyto.2002.1044.

55. Schultz O, Oberhauser F, Saech J, Rubbert-Roth A, Hahn M, Krone $\mathrm{W}$, et al. Effects of inhibition of interleukin-6 signalling on insulin sensitivity and lipoprotein (a) levels in human subjects with rheumatoid diseases. PLoS One. 2010;5(12):e14328. https://doi.org/10. 1371/journal.pone.0014328

56. Berthold HK, Laudes M, Krone W, Gouni-Berthold I. Association between the interleukin-6 promoter polymorphism $-174 \mathrm{G} / \mathrm{C}$ and serum lipoprotein(a) concentrations in humans. PLoS One. 2011;6(9):e24719. https://doi.org/10.1371/journal.pone.0024719.

57. Gabay C, Burmester GR, Strand V, Msihid J, Zilberstein M, Kimura T, et al. Sarilumab and adalimumab differential effects on bone remodelling and cardiovascular risk biomarkers, and predictions of treatment outcomes. Arthritis Res Ther. 2020;22(1):70. https://doi.org/10.1186/s13075-020-02163-6.

58. Team CC-R. Preliminary estimates of the prevalence of selected underlying health conditions among patients with coronavirus disease 2019 - United States, February 12-March 28, 2020. MMWR Morb Mortal Wkly Rep. 2020;69(13):382-6. https://doi.org/10. 15585/mmwr.mm6913e2.

59. Bartel AP, Kim S, Nam J. Racial and ethnic disparities in access to and use of paid family and medical leave: evidence from four nationally representative datasets. Monthly Lab Rev. 2019;142:1.

60. Ferdinand KC, Nasser SA. African American COVID-19 mortality: a sentinel event. J Am Coll Cardiol. 2020. https://doi.org/10.1016/j.jacc. 2020.04.040 An overview of increase morbidity and mortality due to COVID-19 found in the African American population.

61. Tsimikas S, Fazio S, Ferdinand KC, Ginsberg HN, Koschinsky ML, Marcovina SM, et al. NHLBI working group recommendations to reduce lipoprotein(a)-mediated risk of cardiovascular disease and aortic stenosis. J Am Coll Cardiol. 2018;71(2):177-92. https://doi.org/10.1016/j.jacc.2017.11.014.

62. Fan YY, Cai QL, Gao ZY, Lin X, Huang Q, Tang W, et al. APOE epsilon4 allele elevates the expressions of inflammatory factors and promotes Alzheimer's disease progression: a comparative study based on Han and She populations in the Wenzhou area. Brain Res Bull. 2017;132:39-43. https://doi.org/10.1016/j.brainresbull.2017.04.017.

63. Haan MN, Mayeda ER. Apolipoprotein E genotype and cardiovascular diseases in the elderly. Curr Cardiovasc Risk Rep. 2010;4(5): 361-8. https://doi.org/10.1007/s12170-010-0118-4.

64. Howard BV, Gidding SS, Liu K. Association of apolipoprotein E phenotype with plasma lipoproteins in African-American and white young adults. The CARDIA Study. Coronary Artery Risk Development in Young Adults. Am J Epidemiol. 1998;148(9): 859-68. https://doi.org/10.1093/oxfordjournals.aje.a009711.

65. Corbo RM, Scacchi R. Apolipoprotein E (APOE) allele distribution in the world. Is APOE* 4 a 'thrifty'allele? Ann Hum Genet. 1999;63(4):301-10.

66.• Goldstein MR, Poland GA, Graeber CW. Does apolipoprotein E genotype predict COVID-19 severity?. QJM: monthly journal of the Association of Physicians, hcaa142. Advance online publication. 2020. https://doi.org/10.1093/qjmed/hcaa142. A concise review of the potential association of ApoE4 isoforms to COVID-19 response and possible explanation for racial disparity.

67. Rieker C, Migliavacca E, Vaucher A, Baud G, Marquis J, Charpagne A, et al. Apolipoprotein E4 expression causes gain of toxic function in isogenic human induced pluripotent stem cell-derived endothelial cells. Arterioscler Thromb Vasc Biol. 2019;39(9):e195-207. https://doi.org/ 10.1161/atvbaha.118.312261.

68.• Moriarty PM, Varvel SA, Gordts PL, McConnell JP, Tsimikas S. Lipoprotein(a) mass levels increase significantly according to APOE genotype: an analysis of 431239 patients. Arterioscler Thromb Vasc Biol. 2017;37(3):580-8. https://doi.org/10.1161/atvbaha.116.308704 An analysis of greater than 400,000 patients demonstrating the association of lipoprotein(a) mass levels to apoE genotype.

69. Varvel S, McConnell JP, Tsimikas S. Prevalence of elevated Lp (a) mass levels and patient thresholds in 532359 patients in the United States. Arterioscler Thromb Vasc Biol. 2016;36(11):2239-45.

70. Ravandi A, Leibundgut G, Hung MY, Patel M, Hutchins PM, Murphy $\mathrm{RC}$, et al. Release and capture of bioactive oxidized phospholipids and oxidized cholesteryl esters during percutaneous coronary and peripheral arterial interventions in humans. J Am Coll Cardiol. 2014;63(19): 1961-71. https://doi.org/10.1016/j.jacc.2014.01.055.

71. Moriarty PM, Gray JV, Gorby LK. Lipoprotein apheresis for lipoprotein(a) and cardiovascular disease. J Clin Lipidol. 2019;13(6):894-900. https://doi.org/10.1016/j.jacl.2019.09.010.

72. Stefanutti C, Mazza F, Pasqualetti D, Di Giacomo S, Watts GF, Massari MS, et al. Lipoprotein apheresis downregulates IL-1alpha, IL-6 and TNF-alpha mRNA expression in severe dyslipidaemia. Atheroscler Suppl. 2017;30:200-8. https://doi.org/10.1016/j. atherosclerosissup.2017.05.028.

73. Khan TZ, Hsu L-Y, Arai AE, Rhodes S, Pottle A, Wage R, et al. Apheresis as novel treatment for refractory angina with raised lipoprotein (a): a randomized controlled cross-over trial. Eur Heart J. 2017;38(20):1561-9.

74. Tsimikas S, Karwatowska-Prokopczuk E, Gouni-Berthold I, Tardif JC, Baum SJ, Steinhagen-Thiessen E, et al. Lipoprotein(a) reduction in persons with cardiovascular disease. N Engl J Med. 2020;382(3): 244-55. https://doi.org/10.1056/NEJMoa1905239 A phase 2 trial demonstrating the $80 \%$ reduction of lipoprotein(a) with an antisense apolipoprotein(a) pharmacotherapy.

75. Melquist S, Wakefield D, Hamilton H, Chapman C, Grondolsky J, Schienebeck C, et al. Targeting apolipoprotein (a) with a novel RNAi delivery platform as a prophylactic treatment to reduce risk of cardiovascular events in individuals with elevated lipoprotein (a). Circulation. 2016;134(suppl_1):A17167-A.

Publisher's Note Springer Nature remains neutral with regard to jurisdictional claims in published maps and institutional affiliations. 